\title{
Attitudes of University Students in Gaza to Organ Donation
}

Fadil Naim, Ahmed Al-Bahbhani ${ }^{\star}$, Baker Abu Jarad, Ahmed Al-Tayan and Khamis El-Essi

Department of Medicine, Islamic University of Gaza, Palestine

*Corresponding author: Ahmed Al-Bahbhani, Department of Medicine, Islamic University of Gaza, Gaza, Palestine, Tel: +972597982381; Fax: +97082644800; E-mail: Ahmed.bahbhani@hotmail.com

Received date: February 13, 2018; Accepted date: February 26, 2018; Published date: March 05, 2018

Copyright: (c) 2018 Naim F, et al. This is an open-access article distributed under the terms of the Creative Commons Attribution License, which permits unrestricted use, distribution and reproduction in any medium, provided the original author and source are credited.

\section{Abstract}

Background: This study aimed to explore the attitudes and knowledge of university students in Gaza to organ donation.

Methods: A structured questionnaire was used to collect data including socio-demographic characteristics, knowledge level and attitudes of participants toward organ donation and factors that affect personal beliefs of the participants on donation. The questionnaire was distributed using the convenience method to 489 (179 males, 310 females) students at the Islamic University of Gaza. The data were analyzed in a descriptive fashion using SPSS program.

Results: The study showed that $97.5 \%$ of participants were acquainted with the term "organ donation". Those participants were eligible and were asked to complete the questionnaire. Less than half of participants chose multimedia as the main source of information regarding organ donation and more than half of respondents (56\%) said that, "saving lives" was the most important reason for organ donation. One fifth of participants (22\%) reported that they completely reject donating any of their organs during their lifetimes, whereas more than one fourth of them $(27 \%)$ reported that they refuse organ donation even after death. (54\%) of students denied any knowledge about local or international legislation regulating organ donation.

Conclusion: The results of the study confirm the presence of good level of knowledge regarding organ donation among participants, which was reflected in their positive attitudes towards organ donation. However, one of the main concerns to promote organ donation was the fear of surgery and its complications. Additionally, legislative, educational and health agencies are recommended to exert more efforts through the media and public campaigns tackling misconcepts and lack of information regarding organ donation. Finally, ministry of health needs to take steps to alleviate fears and mistrust from the public towards the health care system.

Keywords: Organ donation; Attitudes; Questionnaire

\section{Introduction}

Gaza Strip (GS) is a tiny strip of land along the Mediterranean Sea with around 1.8 million Palestinians inhabitants [1-3]. It has been occupied by Israel in 1967 and still languishing under strict siege since 2007. According to recent numbers from Ministry of Health (MOH) in Gaza in 2015, there are about 550 patients from Gaza who are now in need of renal transplantation and another 550 patients already suffering from renal insufficiency but not yet in need for renal dialysis [4]. Undergoing dialysis is never a good option for Palestinians especially under the difficult conditions in Gaza given the volatile security situation and the daily effects of the blockade including regular power cuts [5].

It is now well known that the best option for patients with renal failure is kidney transplantation. The first kidney transplant surgery in Gaza was successfully carried out on $23^{\text {rd }}$ of January, 2013. It followed a long journey of preparation and training of local medical staff by the transplantation surgery team from the Liverpool International Transplant Initiative, United Kingdom [6].

The success of this transplantation was considered as a long-awaited achievement to end the suffering of patients who suffer from kidney failure and their families. Particular problems encountered this process include the difficulty of travelling abroad, high expenses, and low success rates due to prolonged waiting to cross the borders into and out of Gaza because of the blockade in addition to shortages of drugs including immunosuppressant for kidney-transplanted patients. So far, a total of 23 kidney transplants have been carried out by the international team working with local medical staff, a direct result of the training course provided by the British doctors.

At present, due to lack of legislation in Palestine governing the transfer and transplantation of organs in Gaza, only live donor transplants are possible to be carried out when donor and recipient are close related $[4,7]$. Deceased donor transplants have not been done yet.

Worldwide, thousands of lives are saved by renal transplantation; however, the global demand cannot be met as it greatly exceeds the available supply. Organ supply has been called the Achilles' heel of transplantation. The continuing increase in the number of patients on transplantation waiting lists all over the world is contrasted by stagnancy, or even a decline in the already insufficient supply of organs donation recently $[6,8]$. Globally, there is a shortage of organs donated causing a 'donation gap', and this gap is growing larger every year [8-11]. There is a long waiting list for kidney transplant of almost 
63,000 in the European Union and over 120,000 people in the United States [12-14].

Studies assessing the factors associated with knowledge and attitudes towards organ donation have shown contradicting results and have indicated that it is not clear which specific factors are most significantly related to decision-making for donation $[15,16]$.

In Gaza, thirty percent of the people are young adults aged 15-29. They are the most educated group of people in Gaza, with a $3.7 \%$ illiteracy rate [2]. Studying their opinions and attitudes towards organs donation will assist in future progress in this field in Palestine.

The aim of this study is to assess the attitudes of university students from Gaza to the donation of organs and to investigate potential factors influencing their knowledge and actual behavior regarding organ transplantation. This topic is investigated for the first time in Gaza in this research.

\section{Materials and Methods}

A descriptive analytical study was carried out to determine the attitudes and knowledge of university students from Gaza about organ donation. This study was conducted in May 2015. The researcher used convenience sampling technique in this cross-sectional study in order to get high response rate from students who registered at the Islamic University of Gaza with a sample consisting of 489 students (179 males and 310 females) which is $3.1 \%$ of all university students. The students were stratified into subgroups based on their college, and then $3.1 \%$ of students had been chosen from each subgroup in order to insure equal representation of each college in the sample.

Two participants were excluded from the study because they did not complete questionnaire. Another ten students who have no knowledge regarding organ transplantation were asked not to go on answering the questionnaire. A total of 477 participants successfully completed the questionnaire with a response rate of $97.5 \%$.

The participants were asked to complete a structured questionnaire to obtain detailed information. The questionnaire included closed questions that distributed into 4 sections asked about (sociodemographic characteristics, knowledge level of participants about organ donation, factors potentially influencing the opinion of participants and experience of students who had gone through the process of organ donation). The inclusion criteria were the participants who registered in the Islamic university and previously heard about organ donation.

The questionnaire was completed during face-to-face interview at the university campus by interviewers who are especially trained for the task. Before the administration of the questionnaire, all participants were informed about the aim of the study and that, the Faculty of Medicine at the Islamic University of Gaza carried it out. Participants were reassured about the anonymity and confidentiality of their identity and their responses.

Replies were evaluated using Statistical Package for the Social Sciences software (SPSS version 19). Numerical data were presented as means and ranges. Categorical variables were described using frequency distribution table.

\section{Results}

The mean age of 175 males (37\%) is 20.5 (range: 18-29) while mean age of 302 females (63\%) is 20.3 (range: 18-36).
97.8\% (175 from 179) from male participants heard about organ donation previously. This rate is nearly similar to that of female participants which was $98.1 \%$ (302 from 308).

The main source of information regarding organ donation was Internet as most of students chose. Other sources were: T.V., radio and doctor, respectively (Figure 1).

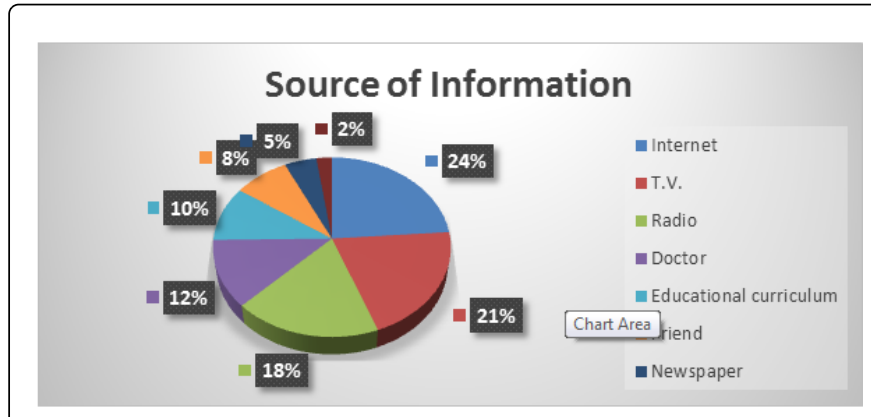

Figure 1: Source of information about organ donation. Valid $=475$, Missing $=2$.

With regard to reasons for organ donation, Table 1 shows that $56 \%$ of participants stated they would agree to donate their organs "to save another human life" while some stated that they would donate their organs for other more personal reasons.

128 female participants (42.3\%) stated that health status of the organ recipient is the major factor that motivate students to donate their organs where 56 male participants (32\%). Other factors are shown in Table 1.

When asked about the possibility of risks in organ donation, almost $86 \%$ of the students selected 'Sometimes' or 'Usually' (Table 1). This is of great concern as this could discourage possible organ donors from donating. There were little to no differences when the results were analyzed by sex.

Following the previous question, the participants were asked "what specific dangers of organ donation they were worried about?". The results show that about $25.6 \%$ of participants were worried about all the possible dangers, while a significant proportion $(22.7 \%)$ of the participants were worried about general weakness of the body. Surprisingly, some stated that there were no dangers that they were worried about as shown in Table 1 .

When asked about their "knowledge of legislation regulating the process of organ donation in Gaza", some stated that they have heard about local legislation while $53.7 \%$ of the study participants have not heard about neither local nor international laws (Table 1).

$57 \%$ of all participants stated that they would be willing to donate their organs during their lifetime under special circumstances, while only $7.2 \%$ of all participants stated that they would definitely be willing to donate their organs regardless of circumstances (Table 1). About $22 \%$ of participants completely rejected the idea of donating their organs during their lifetime, which is a cause for great concern. As for the idea of organ donation after death, $57.0 \%$ answered positively, while $26.7 \%$ refused.

Conversely, the attitudes of respondents toward a relative's organs being donated after their death were more negative, $45.9 \%$ answered 
Citation: Naim F, Al-Bahbhani A, Jarad BA, Al-Tayan A, El-Essi K (2018) Attitudes of University Students in Gaza to Organ Donation. J

Page 3 of 5

"no", while $29.9 \%$ answered "yes". The rest of the study population didn't choose a specific answer and preferred to choose "I don't know".

Regarding the student's knowledge of religious legislation regarding organ donation, about half of the study population showed that they knew about it while the other half did not (Table 1).

The students were asked about their attitudes toward global/local promotion of organ donation. The results are shown in Table 1. The students who disagreed with the promotion of organ donation were then asked about the reasons as to why they disagreed. Most of the answers $(32.1 \%)$ were due to "fear of organ trafficking", followed by "organ corruption or misuse" (23.9\%), "refusal to remove a body part" (12.9\%), "religious convictions" (12.0\%) and "objection of family" $(7.7 \%)$.

\begin{tabular}{|c|c|c|c|c|}
\hline Item & \multicolumn{2}{|c|}{ Frequency $(n=477)$} & \multicolumn{2}{|l|}{$\%$} \\
\hline \multicolumn{5}{|c|}{ Participants' reason for organ donation } \\
\hline Save lives & \multicolumn{2}{|l|}{267} & \multicolumn{2}{|l|}{56.0} \\
\hline Beloved person & \multicolumn{2}{|l|}{84} & \multicolumn{2}{|l|}{17.7} \\
\hline Compassion & \multicolumn{2}{|l|}{62} & \multicolumn{2}{|l|}{13.0} \\
\hline Money & \multicolumn{2}{|l|}{41} & \multicolumn{2}{|l|}{8.6} \\
\hline Others & \multicolumn{2}{|l|}{21} & \multicolumn{2}{|l|}{4.4} \\
\hline Missing & \multicolumn{2}{|l|}{2} & \multicolumn{2}{|l|}{0.4} \\
\hline \multicolumn{5}{|c|}{ Factors that Motivate Students to Donate their Organs } \\
\hline Variables & $\begin{array}{l}\text { Male } \\
(n=175)\end{array}$ & $\begin{array}{l}\text { Female } \\
(n=302)\end{array}$ & Male & Female \\
\hline Health status & 56 & 128 & 32.0 & 42.3 \\
\hline Relationship & 54 & 95 & 30.8 & 31.4 \\
\hline Regardless of any factor & 35 & 37 & 20.0 & 12.2 \\
\hline Age & 10 & 22 & 5.7 & 7.2 \\
\hline $\begin{array}{l}\text { Expectation of low risk for } \\
\text { organ damage by recipient }\end{array}$ & 8 & 16 & 4.5 & 5.2 \\
\hline Religion & 11 & 8 & 6.2 & 2.6 \\
\hline Missing & 1 & 2 & 0.5 & 0.6 \\
\hline \multicolumn{5}{|c|}{ The thought of participants on whether organ donation is risky } \\
\hline Never & \multicolumn{2}{|l|}{5} & \multicolumn{2}{|l|}{1.0} \\
\hline Sometimes & \multicolumn{2}{|l|}{243} & \multicolumn{2}{|l|}{50.9} \\
\hline Usually & \multicolumn{2}{|l|}{168} & \multicolumn{2}{|l|}{35.2} \\
\hline Always & \multicolumn{2}{|l|}{25} & \multicolumn{2}{|l|}{5.2} \\
\hline Don't know & \multicolumn{2}{|l|}{30} & \multicolumn{2}{|l|}{6.2} \\
\hline Missing & \multicolumn{2}{|l|}{6} & \multicolumn{2}{|l|}{1.2} \\
\hline \multicolumn{5}{|l|}{ Dangers of organ donation } \\
\hline All & \multicolumn{2}{|l|}{125} & \multicolumn{2}{|l|}{25.6} \\
\hline General weakness & \multicolumn{2}{|l|}{111} & 22.7 & \\
\hline Inflammation & 64 & & 13.1 & \\
\hline
\end{tabular}

\begin{tabular}{|c|c|c|c|}
\hline \multicolumn{2}{|c|}{ Worry and anxiety } & 58 & 11.9 \\
\hline \multicolumn{2}{|l|}{ Pain } & 49 & 10.0 \\
\hline \multicolumn{2}{|c|}{ Haemorrhage } & 31 & 6.3 \\
\hline \multicolumn{2}{|l|}{ None } & 8 & 1.6 \\
\hline \multicolumn{2}{|l|}{ Others } & 5 & 1.0 \\
\hline \multicolumn{2}{|l|}{ Missing } & 38 & 7.8 \\
\hline \multicolumn{4}{|c|}{ Knowledge of legislation regulation organ donation } \\
\hline \multicolumn{2}{|l|}{ National law } & 34 & 7.1 \\
\hline \multicolumn{2}{|c|}{ International law } & 73 & 15.3 \\
\hline \multicolumn{2}{|l|}{ Both } & 102 & 21.4 \\
\hline \multicolumn{2}{|l|}{ Neither } & 256 & 53.7 \\
\hline \multicolumn{2}{|l|}{ Missing } & 12 & 2.5 \\
\hline \multicolumn{4}{|c|}{ Attitude toward organ donation during participant's lifetime } \\
\hline \multicolumn{2}{|c|}{ Complete rejection } & 104 & 21.8 \\
\hline \multirow[t]{4}{*}{ Acceptance } & $\begin{array}{l}\text { Think about } \\
\text { organ } \\
\text { donation }\end{array}$ & 129 & 35.7 \\
\hline & $\begin{array}{l}\text { Under special } \\
\text { condition }\end{array}$ & 206 & 57.0 \\
\hline & $\begin{array}{l}\text { Acceptance } \\
\text { regardless of } \\
\text { circumstance }\end{array}$ & 26 & 7.2 \\
\hline & total & 361 & 75.7 \\
\hline \multicolumn{2}{|l|}{ Missing } & 12 & 2.5 \\
\hline \multicolumn{4}{|c|}{ Knowledge of religious legislation regarding organ donation } \\
\hline \multicolumn{2}{|l|}{ Yes } & 236 & 49.5 \\
\hline \multicolumn{2}{|l|}{ NO } & 231 & 48.4 \\
\hline \multicolumn{2}{|l|}{ Missing } & 10 & 2.1 \\
\hline \multicolumn{4}{|c|}{ Promotion of organ donation } \\
\hline \multicolumn{2}{|l|}{ Agree } & 171 & 35.8 \\
\hline \multicolumn{2}{|l|}{ Disagree } & 195 & 40.9 \\
\hline \multicolumn{2}{|l|}{ I don't know } & 98 & 20.5 \\
\hline \multicolumn{2}{|l|}{ Missing } & 13 & 2.7 \\
\hline
\end{tabular}

Table 1: Experiences of students who had gone through the process of organ donation.

In the last section of the questionnaire, which explored the experiences of students who had gone through the process of organ donation (not counting blood donation), 7 students stated that they had gone through this process. However, they refused to give any additional information without obvious reason. 


\section{Discussion}

This study aimed to survey students' opinions toward organ donation. Prior to answering questions related to organ donation, the participants had to answer questions focusing on knowledge and awareness of students toward terms related to organ donation. The response to the first question, which assessed the knowledge of students about the term organ donation, (97.5\%) was similar to the result in a developed country such as Sweden (89\%) [10], United Kingdom (95\%) [17]. They are also closely related to the Arabic country Jordan (94.1\%) [18] and Islamic country Pakistan (86\%) [19]. However, the result of Saudi Arabian research that included people who live in cities is surprisingly only (44.6\%) [15], which is extremely low compared to the above-mentioned results. Internet and T.V. were the most important sources of knowledge in the opinion of Palestinian students, despite the bad conditions and blockade of the borders in Gaza strip. Other researches did not mention internet as a source of knowledge, even though, most of these papers were published in recent years. In Germany, for example, $72.1 \%$ of people take their information about organ donation from media [20] and in Jordan, 76\% from TV [18].

As predicted, money was a major reason for organ donation in poor countries such as Pakistan (43.6\%) [19]. Although Gaza is among the most deprived regions in the world with unemployment rate $41.5 \%$ [2], still, Palestinians choose 'saving lives' as the most important reason for organ donation. While the main reason for organ donation in Jordan was the needs of relatives or friend's (85.8\%) [18], in Gaza, as mentioned above, it was to save life regardless the relationship with the recipient. While $90 \%$ of the study participants believed that there is some risks accompanied with organ donation surgery, in a developed country such as the United Kingdom, more than one half $(55.8 \%)$ think there is no risk involved in organ donation [17], In Sweden, the majority $(81 \%)$ of surveyed participants predict healthy life after organ donation surgery [10] and even in Pakistan, 35.4\% of the surveyed people said that there was no risk involved in organ donation [19]. The researcher thought that the reason behind this finding is the low trust in the medical system in Gaza. Therefore, health service providers should put more effort to inform people about organ donation and possible complications to regain trust in the medical system. The study showed that knowledge about the existence of legislations regulating organ donation is low among people in Gaza (47\%) which is comparable to results in other developing countries, like Turkey and Pakistan which was 45\% [9], 49\% [19], respectively. It is thought that the positive attitudes of Palestinian students toward organ donation during their lifetime reflect the spread of awareness about the importance of organ donation to save people's lives. The proof of this point is the high result $(78 \%)$ of people who support donation during the participant's lifetime. The results of researches performed in developed countries were similar to this result UK 76\% [17], Spain $80 \%$ [12], Germany $77.3 \%$ [20].

On the opposite, opinion of Palestinian students differ from their colleagues from Middle East countries as in Saudi Arabia (41.8\%) [15] and Jordan (31.5\%) [18]. On the issue of willingness of donation after death, the rate in our participants was high (57\%). However, this result is lower than the result of willingness to donate during the participants' lifetime. The research suggests that social factors and traditions play a role in explaining this decreased acceptance. Unwillingness of being dissected after death may also be a reason. This result matches the results obtained from other Arabian countries as Jordan and Saudi Arabia which were 58\% [18] and $66.1 \%$ [15], respectively, but it appears low compared to results of MU and UT students in Poland which were $94.5 \%, 85.3 \%$, respectively [21]. The willingness of people in developed countries as Turkey (39.8\%) [9] and Sweden (50\%) [10] were low compared to Arab people. Again, Gaza recorded high in comparison with other nations.

\section{Conclusion}

The study confirmed the good level of awareness and knowledge in addition to a generally-positive attitude toward organ donation among university students. However, one of the main concerns to promote organ donation was the fear of surgery and its complications. Therefore, legislative, educational and health agencies are recommended to exert more efforts through the media and public campaigns tackling misconcepts and lack of information regarding organ donation. Finally, ministry of health needs to take steps to alleviate fears and mistrust from the public towards the health care system.

\section{References}

1. OCHA. "The Gaza Strip: The humanitarian impact of the blockade".

2. http://www.pcbs.gov.ps/portals/_pcbs/PressRelease/ Press_En_IntPopDy2017E.pdf

3. https://theodora.com/wfbcurrent/gaza_strip/gaza_strip_people.html

4. Abdallah Wajeeh Al Qeeshawi (2015) Personal interview with Dr. Abdallah Wajeeh Al Qeeshawi, Head of Palestinian Kidney transplantation team.

5. Slow Death (2016) "The collective punishment of gaza has reached a critical stage". Gaza.

6. HRSA (Health Resources and Services Administration) (2016) Healthcare Systems Bureau, Division of Transplantation. "National Survey of Organ Donation Attitudes and Behaviors".

7. LITI (The Liverpool International Transplant Initiative) (2016) New Report, Gaza.

8. Khan N, Masood Z, Tufail N, Shoukat H, Ashraf KTA, et al. (2011) Knowledge and attitude of people towards organ donation. 2:15-21.

9. Tontus O, Karabey M, Gurdal N (2011) Survey of medical Students attitudes, religious beliefs and knowledge of organ donation. Organs Tissues Cells 14: 203-206.

10. Sanner MA (2002) A Swedish survey of young people's views on organ donation and transplantation. Transpl Int 15: 641-648.

11. Prottas J, Batten H (1988) Health professionals and hospital administrators in organ procurement: Attitudes, reservations, and their resolutions. Am J Public Health 78: 642-645.

12. Scandroglio B, Dominguez-Gil B, Lopez J, Valentin M, Martin M, et al. (2011) Analysis of the attitudes and motivations of the spanish population towards organ donation after death. Transplant Int 24: 158-166.

13. Journalist Workshop on Organ donation and transplantation - Facts and Figures (2014).

14. https://www.unos.org/data/

15. Alghanim S (2010) Knowledge and attitudes toward organ donation in Saudi Arabia: A community-based study comparing rural and urban populations. Saudi J Kidney Dis Transpl 21: 23-30.

16. Irving M, Tong A, Allen R, Wong G (2012) Factors that influence the decision to be an organ donor: A systematic review of the qualitative literature. Nephrol Dial Transplant 27: 2526-2533.

17. Coad L, Carter N, Ling J (2013) Attitudes of young adults from the UK towards organ donation and transplantation. Transplant Res 2: 9.

18. Al Shaikh A, Abu Zaid A, Khader Y (2015) Attitudes of university students in Jordan university of science and technology toward organ donation and their willingness to donate. Jordan Med J 49: 37-43. 
Citation: Naim F, Al-Bahbhani A, Jarad BA, Al-Tayan A, El-Essi K (2018) Attitudes of University Students in Gaza to Organ Donation. J Transplant Technol Res 8: 179. doi:10.4172/2161-0991.1000179

Page 5 of 5

19. Saleem T, Ishaque S, Habib N, Hussain S, Jawed A, et al. (2009) Knowledge, attitudes and practices survey on organ donation among a selected adult population of Pakistan. BMC Med Ethics 10: 5.

20. Bilgel H, Sadikoglu G, Bilgel N (2006) Knowledge and attitudes about organ donation among medical students. Transplantationsmedizin 18: 91-96.
21. Kobus G, Reszec P, Malyszko J, Małyszko J (2016) Opinions and attitudes of university students concerning organ transplantation. Transplant Proc 48: $1360-1364$. 